Check for updates

Cite this: RSC Adv., 2019, 9, 10854

\section{Dual-purpose zinc and silicon complexes of 1,2,3- triazole group substituted phthalocyanine photosensitizers: synthesis and evaluation of photophysical, singlet oxygen generation, electrochemical and photovoltaic properties $\dagger$}

\begin{abstract}
Emre Güzel (DD *
The synthesis, photophysical, singlet oxygen generation, electrochemical and photovoltaic properties of peripheral and axial 1,2,3-triazole group substituted zinc and silicon phthalocyanine complexes with strong absorption in the visible region were described. All novel complexes have been characterized by spectroscopic and electrochemical techniques. All the new compounds are highly soluble in most common organic solvents. The electronic absorption and fluorescence spectral properties of complexes 4 and 5 are investigated. The effects of the triazole group, different metal centers and position of the substituent on the photophysical, electrochemical and photovoltaic properties of the new phthalocyanines were also investigated for the first time in this work. According to the fluorescence measurements, the axially substituted silicon complex (5) showed higher fluorescence quantum yield $\left(\Phi_{\mathrm{F}}=0.28\right)$ than the peripherally substituted zinc complex (4). In addition, quantum yields for singlet oxygen generation $\left(\Phi_{\Delta}=0.32\right.$ for silicon complex (4) and $\Phi_{\Delta}=0.76$ for zinc complex (5) in DMSO) were obtained. Electrochemical studies show that complex 5 is present in non-aggregated form as a result of steric hindrance of the axial groups; the LUMO level of this complex is slightly more negative than the conduction band of $\mathrm{TiO}_{2}$ and electron injection might be less effective. Therefore, the power conversion efficiency of $1.30 \%$ for a complex 4 based dye-sensitized solar cell (DSSC) is higher than complex 5 (0.90\%). Consequently, these zinc and silicon complexes are promising candidates not only for photodynamic therapy but also solar power conversion.
\end{abstract}

Received 31st December 2018 Accepted 1st April 2019

DOI: $10.1039 / \mathrm{c} 8 \mathrm{ra} 10665 \mathrm{~g}$

rsc.li/rsc-advances under varying different trade names such as anastrozole and letrozole for cancer and fluconazole, albaconazole, voriconazole and isavuconazole for anti-fungal treatment. ${ }^{4}$ In addition, derivatives containing the 1,2,3-triazole group are used as antinuclear agents, HIV-1 protease inhibitors, human $\beta 3$ adrenergic receptors, and antituberculosis, antibacterial, miscellaneous, and anticancer agents. ${ }^{5}$ It is also known that pyridine derivatives form a coordination bond with the $\mathrm{TiO}_{2}$ surface. ${ }^{6}$ Therefore, the 1,2,3-triazole groups can be used as anchoring groups such as pyridine derivatives for dye-sensitized solar cells (DSSCs) due to these heterocyclic ligands.

Phthalocyanines (Pcs) have high chemical and thermal stability, and high molar absorption coefficients and exhibit rich and diverse chemistry as well as specific optical, electronic, structural, and coordination properties. There has been great interest in phthalocyanines for use in photodynamic cancer therapy, especially due to their high absorption coefficient where penetration of light into tissue is optimal. The ability to generate reactive oxygen species, as well as these features that mainly produce singlet oxygen in the photodynamic process, have made suitable candidates for photodynamic therapy. Singlet oxygen is considered to be the primary cytotoxic agent 
that plays an important role in the photodynamic therapy of cancer. Single oxygen production requires the irradiation of an appropriate wavelength for stimulation of an effective photosensitizer, dissolved molecular oxygen, and a photosensitizer. A promising photosensitizer should have the ability to perform an efficient intersection transition so that it can transfer energy to underground-state molecular oxygen. ${ }^{7,8} \mathrm{Phthalocyanines}$ are the leading photosensitizers with this property. The first step in PDT treatments is to synthesize suitable photosensitizers and to evaluate the photophysical and photochemical properties of this photosensitizers and to test its usability for the PDT. It is a fact that the metal atom coordinated to the phthalocyanine ring can alter the physical and chemical properties of the complex. ${ }^{9}$ Phthalocyanines with these properties are widely used as photosensitizers in both photodynamic cancer treatment and dye-sensitized solar cell (DSSC) applications.9-12 Particularly zinc and silicon metal coordinated phthalocyanine complexes have been used in the photodynamic therapy of cancer owing to the closed shell, diamagnetic ion (such as $\mathrm{Si}^{4+}$, $\mathrm{Zn}^{2+}$ ) give both high triplet quantum yields and long lifetimes. ${ }^{13-16}$ Also due to this diamagnetic metal properties, zinc phthalocyanines that have been studied widely by many groups are very important photosensitizers for DSSC applications. In addition, Zn(II) phthalocyanine complexes are used as photosensitizers owing to their long-lived ( $>1 \mathrm{~ns}$ ) singlet excited states. Metal-free porphyrins and phthalocyanines are generally more ineffective photosensitizers than $\mathrm{Zn}$ (II) analogs and show a significant decrease in photo-current response due to low excited singlet states (the oxidation potential of free bases are generally more positive whereas the HOMO-LUMO gaps stay similar). ${ }^{17}$

Chemical structure of substituents which are attached to the peripheral or non-peripheral positions of phthalocyanines significantly change their properties such as absorption behavior and solubility. ${ }^{9,18-23}$ According to the positions of the substituents, it is readily understood that two different tetrasubstituted phthalocyanines differ significantly in their photophysical and photochemical behaviors. Similarly, metal atoms coordinated to the phthalocyanine center are known to alter the electrochemical properties of the compound. The applications of the metallophthalocyanine complexes are almost entirely based on electron transfer reactions due to the $18 \pi$-electronconjugated system. In many applications of phthalocyanines, it is important to have a good understanding of the redox properties of these compounds. ${ }^{24-26}$

Taking these properties into consideration, it has focused on non-aggregate complexes as a strategy to explain Pcs in conjunction with the 1,2,3-triazole group to study aggregation, photophysical, singlet oxygen generation, electrochemical and photovoltaic properties. Besides the electrochemical behavior of MPcs was investigated so as to support the proposed structure. Determination of the electrochemical behavior of complexes will be important in assessing the possible use of complexes in different electrochemical fields such as electrocatalysis and electrosensing. In the literature, there are only few studies about the synthesis of 1,2,3-triazole-substituted phthalocyanines, ${ }^{27}$ despite there are many important studies about 1,2,4-triazole-substituted phthalocyanines. ${ }^{28-31}$ In addition, photo-physicochemical and electrochemical properties of phthalocyanines have widely known but the examination of these properties have been made for only few of 1,2,3-triazole bearing phthalocyanines. There are no studies examining and comparing all the photophysical, singlet oxygen generation, electrochemical and photovoltaic properties of peripheral substituted zinc and axial substituted silicon phthalocyanine complexes. Also, to the best of our knowledge, there is no report on the utilization of 1,2,3-triazole unit as an anchoring group into a dye molecule for DSSCs. This is the first study using the 1,2,3-triazole group as an anchoring group in DSSCs. Therefore, 1,2,3-triazole-substituted silicon and zinc phthalocyanines were designed and prepared. Also, their photo-physicochemical, electrochemical and photovoltaic properties were investigated.

\section{Experimental}

The used equipment, materials, and the photophysical, photochemical, electrochemical and photovoltaic parameters were supplied as ESI. $\dagger$

\subsection{Synthesis}

2.1.1. 6-((1-Phenyl-1H-1,2,3-triazol-5-yl)methoxy)hexan-1-ol (2). (1-Phenyl-1H-1,2,3-triazol-5-yl)methanol (3.5 g, $0.02 \mathrm{~mol}$ ) dissolved in ethanol (25 mL), KOH (1.44 g, $0.025 \mathrm{~mol})$ was added in it by stirring at $45{ }^{\circ} \mathrm{C}$ for $1 \mathrm{~h}$ and then, 6-chlorohexan-1-ol $(2.72 \mathrm{~g}, 0.02 \mathrm{~mol})$ in ethanol $(5 \mathrm{~mL})$ was added drop by drop to the first solution while stirring efficiently for $1 \mathrm{~h}$. After this product was refluxed for $48 \mathrm{~h}$ under a nitrogen atmosphere and then reaction cooled. The solvent in the reaction medium was removed by vacuum and the obtained crude product was dissolved in $\mathrm{CHCI}_{3}(80 \mathrm{~mL})$ and cleaned three times with $10 \%$ $\mathrm{NaOH}(2.15 \mathrm{~mL})$ and three times with water $(100 \mathrm{~mL})$. The organic phase was dried with $\mathrm{MgSO}_{4}$, filtered and evaporated. The crude product was purified with an aluminum oxide column using $\mathrm{CHCI}_{3}$ as a solvent. The oily yellow product was dried in vacuo $\left(\mathrm{P}_{2} \mathrm{O}_{5}\right)$. This product was soluble in $\mathrm{THF}, \mathrm{CHCl}_{3}$, $\mathrm{CH}_{2} \mathrm{Cl}_{2}$, DMF, and DMSO. Yield: $3.3 \mathrm{~g}(60 \%)$. FT-IR $\left(\nu_{\max } / \mathrm{cm}^{-1}\right)$ : 3372 (-O-H), 3103 (Ar-C-H), 2934-2861 (Aliph. -C-H), 1599 (Ar$\mathrm{C}=\mathrm{C}), 1503,1447(-\mathrm{N}=\mathrm{N}$ triazole $), 1352(-\mathrm{C}-\mathrm{N}$ triazole) 1232, 1109, 1044, 759, 691, 522. ${ }^{1} \mathrm{H}-\mathrm{NMR}\left(300 \mathrm{MHz}, \mathrm{CDCl}_{3}\right): \delta 7.99(\mathrm{~s}$, $1 \mathrm{H}), 7.69(\mathrm{~m}, 2 \mathrm{H}), 7.47(\mathrm{~m}, 3 \mathrm{H}), 4.83(\mathrm{~s}, 2 \mathrm{H}), 3.49(\mathrm{~m}, 4 \mathrm{H}), 1.30$ $(\mathrm{m}, 8 \mathrm{H}) .{ }^{13} \mathrm{C}-\mathrm{NMR}\left(75 \mathrm{MHz}, \mathrm{CDCl}_{3}\right): \delta$ 137.16, 129.99 (overlapped 2C signals), 129.06, 120.77 (overlapped 2C signals), 120.39, 70.86, 64.46, 62.98, 32.84, 29.79, 26.13, 25.76. Anal. calc. for $\mathrm{C}_{15} \mathrm{H}_{21} \mathrm{~N}_{3} \mathrm{O}_{2}$ : C, 65.43; H, 7.69; N, 15.26; O, 11.62; found: $\mathrm{C}$, 65.13; H, 7.39; N, 15.46; O, 11.62. MS MALDI-TOF: $m / z 275.82$ $[\mathrm{M}]^{+}$.

2.1.2. 4-((1-Phenyl-1H-1,2,3-triazol-5-yl)methoxy)phthalonitrile (3). 4-Nitrophthalonitrile (2.0 g, $11.2 \mathrm{mmol})$ and (1-phenyl-1H-1,2,3triazol-5-yl)methanol (1.96 g, $11.6 \mathrm{mmol}$ ) were dissolved in $40 \mathrm{~mL}$ $\mathrm{DMF}$ at $45^{\circ} \mathrm{C}$ under argon atmosphere. To the reaction mixture was added 5 portions of potassium carbonate $(9 \mathrm{~g}, 65.2 \mathrm{mmol})$ every 8 hours. After stirring for 48 hours, the mixture was slowly cooled to room temperature. It was then poured into $250 \mathrm{~mL}$ of ice-water 
mixture. After filtration, the crude product was purified by using column chromatography on silica gel (methanol/chloroform 1/50). Yellowish-white product was soluble in ethylacetate, $\mathrm{THF}, \mathrm{CHCl}_{3}$, $\mathrm{CH}_{2} \mathrm{Cl}_{2}$, and DMF. Yield: $1.38 \mathrm{~g}$, (42\%). FT-IR $\left(\nu_{\text {max }} / \mathrm{cm}^{-1}\right): 3078(\mathrm{Ar}-$ $\mathrm{C}-\mathrm{H}), 2984$ (Aliph. $-\mathrm{C}-\mathrm{H}), 2230(-\mathrm{C} \equiv \mathrm{N}), 1602(\mathrm{Ar}-\mathrm{C}=\mathrm{C}), 1564$, 1490, 1405 ( $-\mathrm{N}=\mathrm{N}$ triazole), 1309 ( $\mathrm{C}-\mathrm{N}$ triazole), 1254 ( $\mathrm{R}-\mathrm{O}-\mathrm{Ar})$, 1008, 759, 685, 526. ${ }^{1} \mathrm{H}-\mathrm{NMR}\left(300 \mathrm{MHz}, \mathrm{CDCl}_{3}\right): \delta 8.11(\mathrm{~s}, 1 \mathrm{H}), 7.75$ (m, 3H), 7.48 (m, 5H), 5.40 (s, 2H). ${ }^{13} \mathrm{C}-\mathrm{NMR}$ (75 MHz, CDCl3): $\delta$ 161.38, 142.80, 136.88, 135.61, 130.14 (overlapped 2C signals), 129.51, 121.88, 120.87 (overlapped 2C signals), 120.55, 119.74, 117.72, 115.78, 115.37, 108.16, 62.74. Anal. calc. for $\mathrm{C}_{17} \mathrm{H}_{11} \mathrm{~N}_{5} \mathrm{O}: \mathrm{C}$, 67.77; H, 3.68; N, 23.24; O, 5.31; found: C, 66.04; H, 3.33; N, 23.66; O, 5.55. MS MALDI-TOF: $m / z 301.43[\mathrm{M}]^{+}$.

2.1.3. Zinc(II) phthalocyanine (4). A mixture of 4-((1-phenyl$1 H$-1,2,3-triazol-5-yl)methoxy)phthalonitrile $(0.100 \mathrm{~g}, \quad 0.332$ $\mathrm{mmol})$, anhydrous $\mathrm{Zn}\left(\mathrm{CH}_{3} \mathrm{COO}\right)_{2}(0.041 \mathrm{~g}, 0.234 \mathrm{mmol})$ and DBU $(0.25 \mathrm{mmol})$ in amyl alcohol $(2 \mathrm{~mL})$ was refluxed at $140{ }^{\circ} \mathrm{C}$ for 8 hours. The mixture was cooled to room temperature and precipitated by addition of $n$-hexane. The product was washed with hot ethanol, acetone and ethyl acetate in order to remove the impurities. The targeted pure product was obtained by basic silica gel column chromatography using a gradient of chloroform/ethanol (9/1). Yield: $0.036 \mathrm{~g}$, (35\%). FT-IR $\left(\nu_{\max } /\right.$ $\mathrm{cm}^{-1}$ ): 3102 (Ar-C-H), 2958-2871 (Aliph. $\left.-\mathrm{C}-\mathrm{H}\right), 1608(\mathrm{Ar}-\mathrm{C}=$ C), 1487, 1405, 1337 (-C-N triazole), 1232 (R-O-Ar), 1038, 948, 819, 744, 643, 470. UV-Vis $\lambda_{\max }$ (nm) THF: 676, 610, 348. ${ }^{1} \mathrm{H}-$ NMR (300 MHz, $\left.\mathrm{CDCl}_{3}\right)$ : $\delta, \operatorname{ppm} 9.18(\mathrm{~s}, 4 \mathrm{H}$, Triazole $\mathrm{Ar}-\mathrm{H})$, 8.84-7.46 (32H, m, Pc-Ar-H, and $\mathrm{Ar}-\mathrm{H}), 5.75\left(8 \mathrm{H}, \mathrm{s}, \mathrm{OCH}_{2}\right)$. Anal. calc. for $\mathrm{C}_{68} \mathrm{H}_{44} \mathrm{~N}_{20} \mathrm{O}_{4} \mathrm{Zn}$ : C, 64.28; H, 3.49; N, 22.05; O, 5.04; Zn, 5.15; found: C, 64.04; H, 3.33; N, 22.66. MS MALDITOF: $m / z 1270.50[\mathrm{M}]^{+}$.

2.1.4. Silicon(Iv) phthalocyanine (5). A mixture of unsubstituted dichloro[phthalocyaninato]silicon $(50 \mathrm{mg}, \quad 0.0817$ $\mathrm{mmol}), \mathrm{NaH}$ (0.735 mmol, $17.5 \mathrm{mg})$ and 6-((1-phenyl-1H-1,2,3triazol-5-yl)methoxy)hexan-1-ol $(66.21 \mathrm{mg}, 0.244 \mathrm{mmol})$ in dry toluene $(20 \mathrm{~mL})$ was refluxed for $8 \mathrm{~h}$ under $\mathrm{N}_{2}$ atmosphere. The reaction mixture was centrifuged, the filtrate removed and the residue washed with $n$-hexane $(2 \times 40 \mathrm{~mL})$ and dried in vacuo. The obtained crude product was purified by aluminum oxide column chromatography and using dichloromethane/methanol (20/1) as eluent. Yield: $57 \mathrm{mg}(64.1 \%)$. FT-IR $\left(\nu_{\max } / \mathrm{cm}^{-1}\right): 3081$ (Ar-C-H), 2929-2849 (Aliph. -C-H), 1601 (Ar-C=C), 1519, 1433, $1428(-\mathrm{N}=\mathrm{N}$ triazole), 1332 ( $-\mathrm{C}-\mathrm{N}$ triazole), 1291, 1024, 909, 736, 645, 573, 530. UV-Vis $\lambda_{\max }(\mathrm{nm}) \mathrm{THF}: 671,605,354 .{ }^{1} \mathrm{H}-$

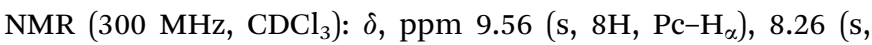
$\left.8 \mathrm{H}, \mathrm{Pc}-\mathrm{H}_{\beta}\right), 7.92-7.26(\mathrm{~m}, 2 \mathrm{H}$, triazole $\mathrm{Ar}-\mathrm{H}$ and $\mathrm{m}, 10 \mathrm{H}$, benzene $\mathrm{Ar}-\mathrm{H}), 4.61-(-1.76)\left(\mathrm{m}, 28 \mathrm{H}, \mathrm{CH}_{2}-\mathrm{O}\right.$ and Aliph. $\left.\mathrm{CH}\right)$. Anal. calc. for $\mathrm{C}_{62} \mathrm{H}_{56} \mathrm{~N}_{14} \mathrm{O}_{4} \mathrm{Si}$ : C, 68.36; H, 5.18; N, 18.00; O, 5.87; Si, 2.58; found: C, 68.04; H, 5.33; N, 18.66. MS MALDI-TOF: $\mathrm{m} / \mathrm{z}$ $1095.95[\mathrm{M}+6 \mathrm{H}]^{+}$.

\section{Results and discussion}

\subsection{Synthesis and characterization}

Scheme 1 exhibits the synthetic route of peripherally substituted zinc and diaxially substituted silicon phthalocyanines 4 and 5. Firstly, the 1,3-dipolar cycloaddition reaction of azidobenzene and propargyl alcohol gave the starting material compound 1 in $89 \%$ yield. Secondly, 6-((1-phenyl-1H-1,2,3triazol-5-yl)methoxy)hexan-1-ol (2) was synthesized by treating (1-phenyl-1H-1,2,3-triazol-5-yl)methanol ${ }^{32} \quad$ (1) with 6chlorohexan-1-ol in ethanol at reflux temperature utilizing $\mathrm{NaOH}$ as the base. Thirdly, (1-phenyl-1H-1,2,3-triazol-5-yl) methanol (1) was treated with 4-nitrophthalonitrile in the presence of anhydrous $\mathrm{K}_{2} \mathrm{CO}_{3}$, giving phthalonitrile derivative containing 1,2,3-triazole group (3). Lastly, targeted peripherally substituted zinc (4) and axially substituted silicon complex (5) were prepared using starting materials 2 and 3. For zinc complex, the reaction in the presence of DBU or 1,5-diazabicyclo [4.3.0]non-5-ene (DBN) either in $n$-hexanol or in bulk is most efficient in comparison to another method. Therefore, ZnPc complex (4) was obtained by utilizing the anhydrous metal salt $\left[\mathrm{Zn}\left(\mathrm{CH}_{3} \mathrm{COO}\right)_{2}\right]$ in $n$-hexanol in the presence of DBU at reflux temperature, the reaction color turned dark blue and the reaction was stopped. To obtain a precipitate, the mixture was washed with different amounts of water and methanol. The new axially disubstituted SiPc complex (5) was prepared by heating from silicon phthalocyanine dichloride $\left(\mathrm{SiCl}_{2} \mathrm{Pc}\right)$ and $6-((1-$ phenyl-1H-1,2,3-triazol-5-yl)methoxy)hexan-1-ol in the presence of $\mathrm{NaH}$ in toluene at $120{ }^{\circ} \mathrm{C}$ for $6 \mathrm{~h}$.

The complexes $\mathbf{4}$ and $\mathbf{5}$ are generally soluble in organic solvents and can be readily purified by column chromatography using silica gel or $\mathrm{Al}_{2} \mathrm{O}_{3}$. The structures of the newly synthesized and well-purified compounds were elucidated by UV-Vis, FT-IR, ${ }^{1} \mathrm{H}-\mathrm{NMR},{ }^{13} \mathrm{C}-\mathrm{NMR}$ and MS spectroscopic methods. The results show that the synthesized compounds are coherent with the proposed structures.

The presence of 1,2,3-triazole groups in compound 2, phthalonitrile (3) and its zinc and silicon complexes (4 and 5) were confirmed by FT-IR analysis. Unlike 1,2,4-triazole groups, 1,2,3-triazole groups have stretching vibrations belonging to $-\mathrm{N}=\mathrm{N}$ groups instead of $-\mathrm{C}=\mathrm{N}$, and they appeared around at around $1450 \mathrm{~cm}^{-1}$ like compound 2 in the FT-IR spectrum. Furthermore, the peak at $1352 \mathrm{~cm}^{-1}$ of the compound (2) containing 1,2,3-triazole group proved the presence of $-\mathrm{C}-\mathrm{N}$ bonds in the structure (Fig. S1†). For compound 3, stretching vibrations of $-\mathrm{C} \equiv \mathrm{N}$ at $2230 \mathrm{~cm}^{-1}$, aliphatic $-\mathrm{C}-\mathrm{H}$ at $2971-2872 \mathrm{~cm}^{-1}$ and $-\mathrm{C}-\mathrm{N}$ at $1309 \mathrm{~cm}^{-1}$ appeared at the expected frequencies. Also, the formation of compound 3 was confirmed by the disappearance of the $-\mathrm{OH}$ bands at $3372 \mathrm{~cm}^{-1}$ for $\mathbf{1}$ (Fig. S5 $\dagger$ ). Cyclotetramerization of the dinitrile 3 was confirmed by the absence of the sharp $-\mathrm{C} \equiv \mathrm{N}$ vibration around $2230 \mathrm{~cm}^{-1}$ after zinc phthalocyanine complex (4) formation (Fig. S9†). Similarly, the formation of silicon phthalocyanine 5 was confirmed by the disappearance of the $-\mathrm{OH}$ band at $3372 \mathrm{~cm}^{-1}$ for 2 in the FT-IR spectrum of silicon phthalocyanine 5 (Fig. S12†). Generally, FTIR spectra for both zinc complex $\mathbf{4}$ and silicon complex $\mathbf{5}$ support the structures of the complexes.

The ${ }^{1} \mathrm{H}$-NMR spectra are also compatible with the structures of the synthesized compounds. The ${ }^{1} \mathrm{H}-\mathrm{NMR}$ spectra of compounds 2-5 in $\mathrm{CDCI}_{3}$ gave the characteristic signals for the structures as expected. In the ${ }^{1} \mathrm{H}$-NMR spectrum of compound 2, one proton belonging to the 1,2,3-triazole ring was observed at $7.99 \mathrm{ppm}$ as a singlet. Benzene protons were observed as 


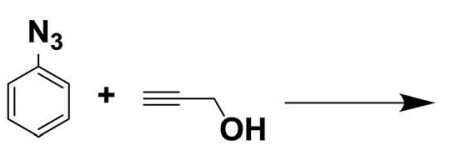<smiles>OCc1cnnn1-c1ccccc1</smiles>

1

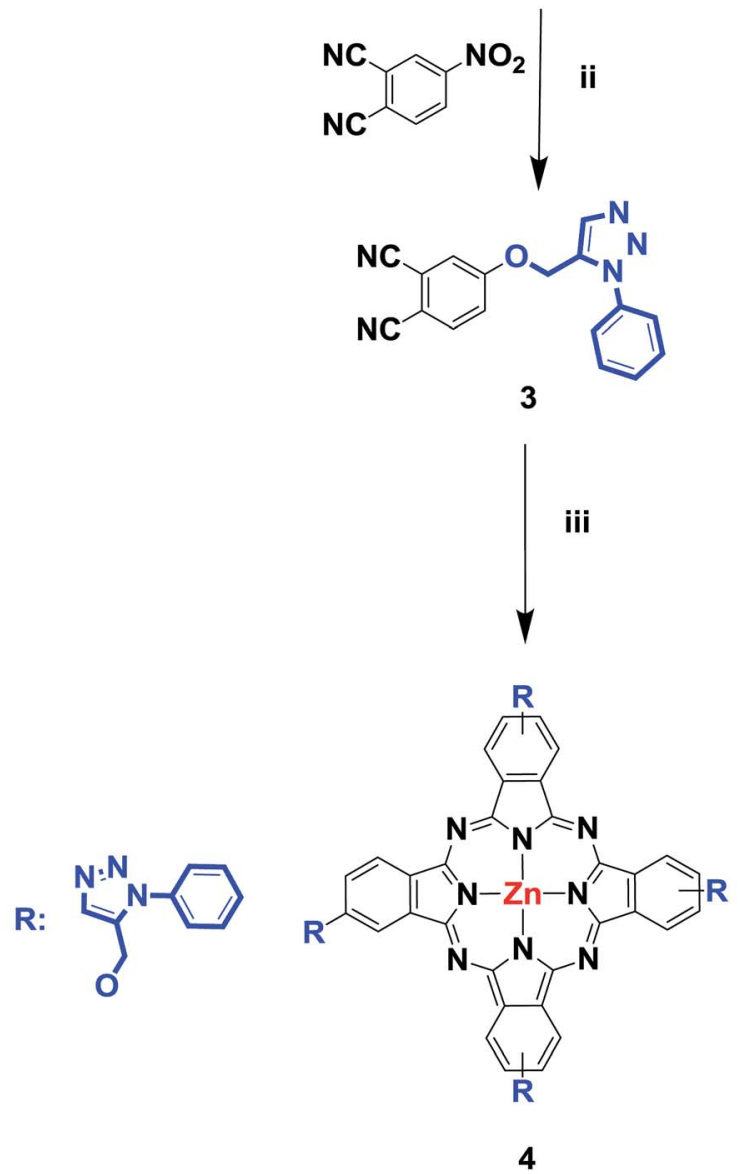

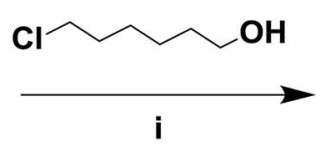

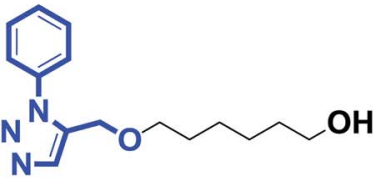

2

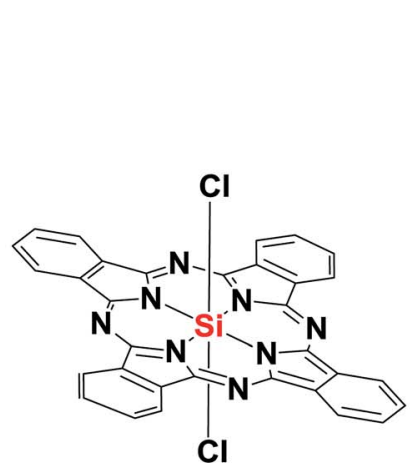

iv

Scheme 1 The synthesis of compound 1, 2, phthalonitrile derivative 3 and it's zinc and silicon complexes (4 and 5) (i) $\mathrm{NaOH}$, EtOH, $80{ }^{\circ} \mathrm{C}$. (ii) $\mathrm{K}_{2} \mathrm{CO}_{3}, \mathrm{DMF}, 45^{\circ} \mathrm{C}$. (iii) $\mathrm{DBU}, n$-pentanol, $\mathrm{Zn}\left(\mathrm{CH}_{3} \mathrm{COO}\right)_{2}, 140{ }^{\circ} \mathrm{C}$. (iv) Toluene, $\mathrm{NaH}, 120^{\circ} \mathrm{C}$.

multiplet at 7.69-7.47 ppm integrating five protons. Aliphatic protons were observed at 4.83-1.30 ppm (Fig. S2 $\dagger$ ). In ${ }^{13} \mathrm{C}-\mathrm{NMR}$ spectrum of compound 2 , the aromatic and aliphatic carbons appeared at 137.16, 129.99 (overlapped 2C signals), 129.06, 120.77 (overlapped 2C signals), 120.39, 70.86, 64.46, 62.98, 32.84, 29.79, 26.13, 25.76 ppm (Fig. S3†). In the ${ }^{1} \mathrm{H}$-NMR spectrum of compound 3, one proton belonging to the 1,2,3-triazole ring was observed at $8.11 \mathrm{ppm}$ as a singlet. Benzene protons were observed as multiplet at 7.75-7.48 ppm integrating eight protons. One singlet peak for $\mathrm{OCH}_{2}$ integrating two protons observed at $5.40 \mathrm{ppm}$ (Fig. S6 $\dagger$ ). In ${ }^{13} \mathrm{C}-\mathrm{NMR}$ spectrum of compound 3, fifteen aliphatic and aromatic carbons and two nitrile carbons appeared at 161.38, 142.80, 136.88, 135.61, 130.14 (overlapped 2C signals), 129.51, 121.88, 120.87 (overlapped 2C signals), 120.55, 119.74, 117.72, 115.78, 115.37, 108.16, 62.74 ppm (Fig. S7†). The ${ }^{1} \mathrm{H}-\mathrm{NMR}$ spectrum of 4 is somewhat broader than the corresponding chemical shifts in the dinitrile derivative $3 .{ }^{1} \mathrm{H}$-NMR spectra of phthalocyanines are of broad nature, because of the presence of four positional isomers which tend to show similar chemical shifts. The second reason for broad signals is that phthalocyanines show an equilibrium of aggregation and disaggregation. In the ${ }^{1} \mathrm{H}-\mathrm{NMR}$ spectrum of zinc complex 4 , four protons belonging to the 1,2,3triazole ring was observed at $9.18 \mathrm{ppm}$ as a singlet. Aromatic benzene protons of phthalocyanine and 1,2,3-triazole rings were observed as multiplet at 8.84-7.46 ppm. One singlet peak for $\mathrm{OCH}_{2}$ integrating eight protons observed at $5.75 \mathrm{ppm}$ (Fig. S10 $\dagger$ ). The ${ }^{1} \mathrm{H}-\mathrm{NMR}$ measurement of silicon phthalocyanine complex 5 showed the expected total number of aliphatic and aromatic protons, confirming the purity of the complex. The ${ }^{1} \mathrm{H}$-NMR spectrum of silicon phthalocyanine complex 5 showed $\mathrm{H}_{\alpha}$ and $\mathrm{H}_{\beta}$ aromatic protons between 9.56 and $8.26 \mathrm{ppm}$. The other protons belonging to the 1,2,3-triazole ring and benzene protons were observed between 7.92 and $7.26 \mathrm{ppm}$. Aliphatic protons were observed $4.61-(-1.76) \mathrm{ppm}$ (Fig. S13†). ${ }^{1} \mathrm{H}-\mathrm{NMR}$ spectrum of $5, \mathrm{Si}-\mathrm{O}-\mathrm{CH}_{2}$ has shifted 
negative area $(-1.76 \mathrm{ppm})$ because of magnetic anisotropy of phthalocyanine ring. ${ }^{33}$

The mass spectra of derivatives, which were obtained by MALDI-TOF techniques, confirmed the proposed structures. By using the instrument's reflectron mode to compare the theoretical and experimental monoisotopic $\mathrm{m} / \mathrm{z}$ values of the compounds and starting materials, the highly resolved signals of each species in the MALDI-TOF mass spectra were well obtained. After evaluation of the MALDI-TOF mass spectra, it was found that the desired starting compounds and complexes were successfully purified using the experimental methods expressed in this study. In addition, it has been found that the synthesized compounds are sufficiently stable to detect structures without significant fragmentation under the conditions of MALDI-MS. The molecular ion peaks were observed at $m / z: 275.85[\mathrm{M}]^{+}$for 2 (Fig. S4†), $301.43[\mathrm{M}]^{+}$for 3 (Fig. S8 $\dagger$ ), $m / z: 1270.50[\mathrm{M}]^{+}$for 4 (Fig. 1), $1095.98[\mathrm{M}+6 \mathrm{H}]^{+}$for 5 (Fig. $\mathrm{S} 14 \dagger$ ).

\subsection{Photophysical and photochemical studies}

3.2.1. Ground state electronic absorption spectra and aggregation studies. UV-Vis spectra of the phthalocyanines shows characteristic absorptions in the Q-band region at around $680-700 \mathrm{~nm}$, attributed to the $\pi-\pi *$ transition from the HOMO to the LUMO of the Pc ring, and in the B band region (UV region) at around $350-360 \mathrm{~nm}$, arising from the deeper $\pi-$ $\pi *$ transitions. As it is expected that the UV-Vis absorption spectra of the blue colored axial silicon and green colored peripheral zinc phthalocyanine complexes in THF exhibited two main peaks, the characteristic ligand centered $\pi-\pi^{*}$ transitions of a monomeric phthalocyanines $\mathbf{4}$ and $\mathbf{5}$ with the B-band and Q-band maxima at 347, $353 \mathrm{~nm}(\log \varepsilon=4.77$ and 4.56) and 676, $671 \mathrm{~nm}(\log \varepsilon=4.86$ and 4.89), respectively (Fig. 2).

It is known that the central metal ions in the phthalocyanine macrocycle can change the maximum value of the $\mathrm{Q}$ band maximum. In porphyrins present in the same family as phthalocyanine complexes, the blue shift of the $\mathrm{Q}$ band differs

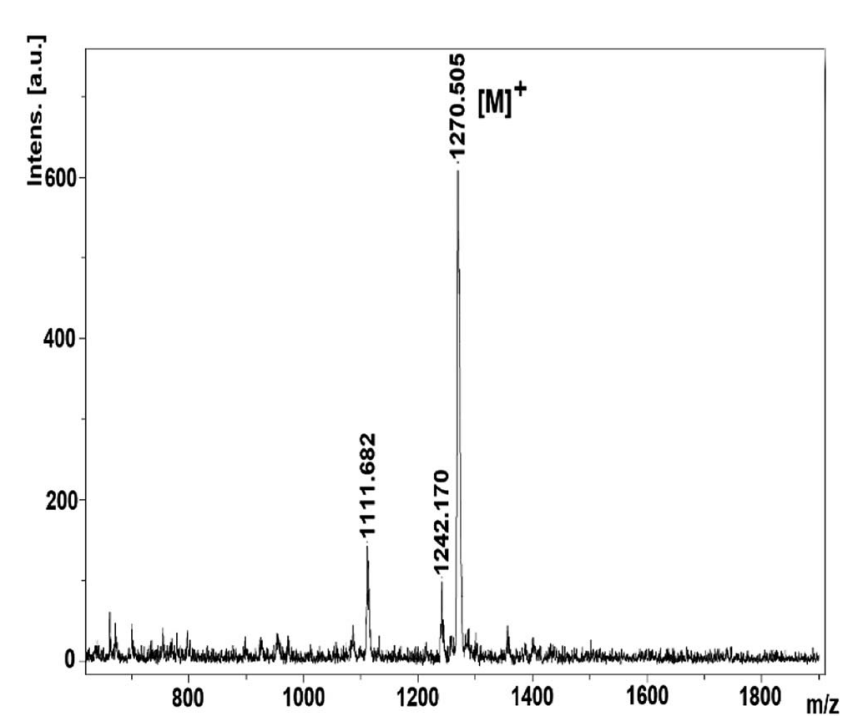

Fig. 1 The mass spectrum of the 1,2,3-triazole group substituted zinc phthalocyanine (4).

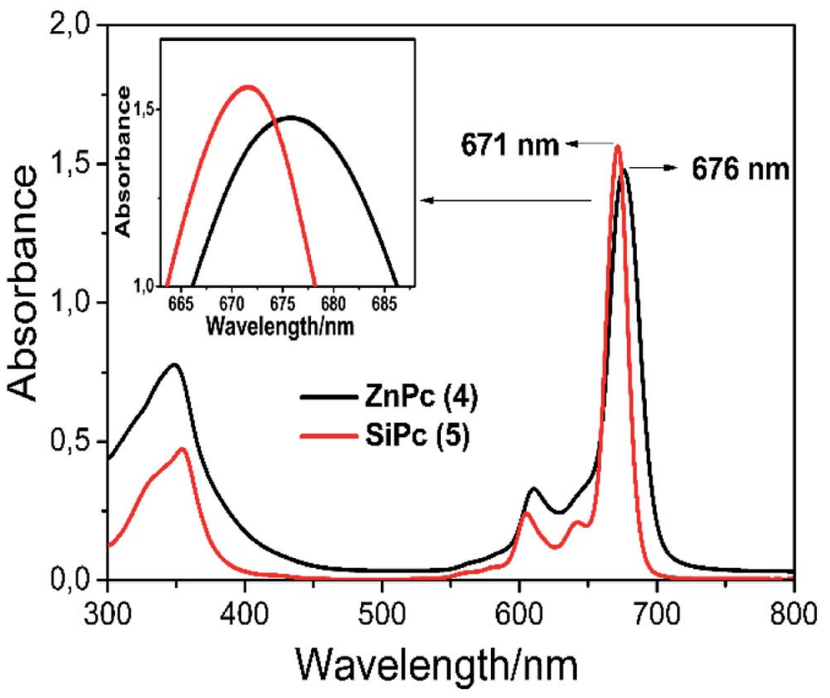

Fig. 2 Absorption spectra of complexes 4 and 5 in THF $(\sim 2 \times$ $10^{-5} \mathrm{~mol} \mathrm{dm}^{-3}$ ).

according to the ionic radius of the central metal ions and the electronegativity. Briefly, a larger electronegativity value or smaller ionic radius results in a shift to blue wavelength. ${ }^{34}$ It can be seen that the $\lambda_{\max }$ of complex 5 exhibits a blue shift with respect to complex 4 owing to the $\mathrm{Si}$ (Iv) ion has a smaller radius and larger electronegativity than the $\mathrm{Zn}$ (II) ion. As a result, the wavelengths of the Q-band absorption of the MPcs follow the order of $\mathrm{Zn}>\mathrm{Si}$ (Fig. 2).

When the dyes are adsorbed on the $\mathrm{TiO}_{2}$ film without chenodeoxycholic acid (CDCA) as the co-adsorbent, the Q-band absorption maxima are red shifted by $\sim 10 \mathrm{~nm}$ compared with those in THF solution (Fig. 3). This result indicates that the interaction of 1,2,3-triazole moiety and $\mathrm{TiO}_{2}$ surface, which is similar to that reported in the interaction of the pyridine ring of the D- $\pi-\mathrm{A}$ fluorescent dyes with $\mathrm{TiO}_{2}$ surface. ${ }^{6}$ The spectrum of dye 4 exhibits the broadened Q-band and a new peak at around $635 \mathrm{~nm}$, demonstrating the existence of molecular aggregates on the semiconductor surface. ${ }^{35}$ By the addition of the coadsorbent to the dye solution, the absorption intensity of the new band relative to that of the Q-band remarkable decreased, which suggests that the aggregation of dye 4 on the $\mathrm{TiO}_{2}$ surface was suppressed by CDCA co-sensitization. In contrast, the spectra of dye 5 with and without CDCA show that there is little or no dye aggregation, indicating that the aggregate formation can be effectively hindered by the steric effect of long and flexible axial 1,2,3-triazole group in the molecule.

Aggregation can often be expressed as the superposition of monomers, dimers, and rings in the solvent medium. There are lots of parameters for aggregation in phthalocyanines; concentration, the nature of the solvent, substituents present at the periphery or non-periphery, the metal ion at the macrocyclic core, and the operating temperature. In order to better examine the solubility and aggregation properties of the complexes, the aggregation study was also performed at ambient temperature in THF. The absorption spectra of phthalocyanines 4 and 5 were also obtained at different concentrations and Fig. 4 shows the 

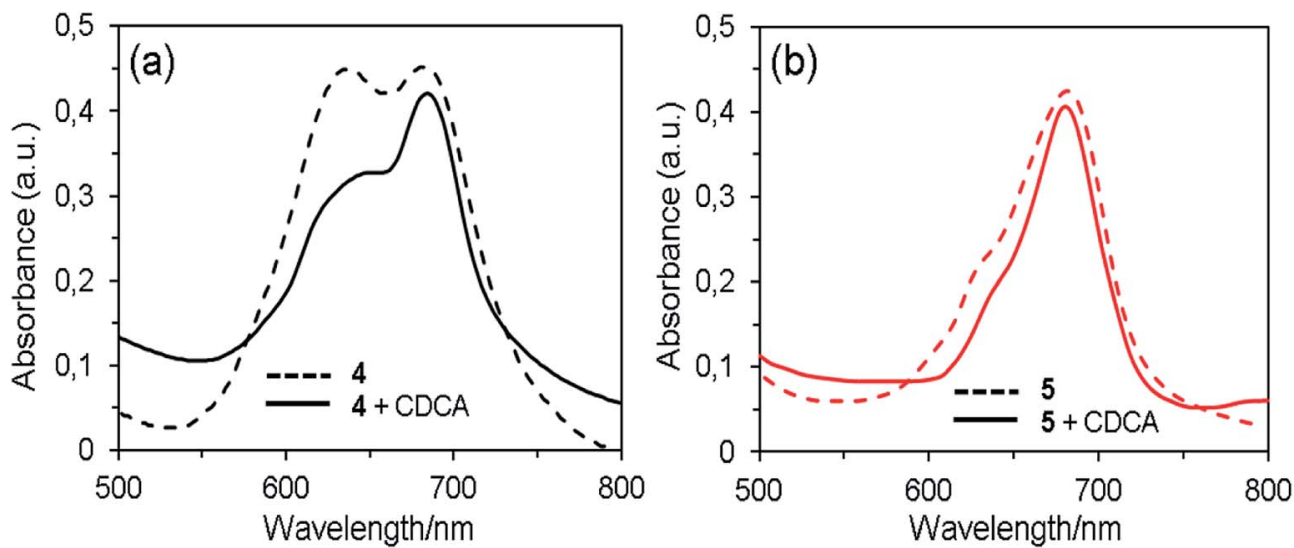

Fig. 3 UV-Vis absorption spectra of 4 (a) and 5 (b) without and with $1 \mathrm{mM} \mathrm{CDCA}$ on $\mathrm{TiO}_{2}$ film.

results for complex 5. Axial substituted silicon phthalocyanine and peripheral substituted zinc phthalocyanine did not aggregate in THF at studied concentrations (Fig. S15 concentration increased, a new band did not form on the high energy side owing to the formation of aggregate species, and the absorption intensity of the $\mathrm{Q}$ band was consistent with the Lambert-Beer's law (inset of Fig. 4).

Solvents may interact with absorbing species in the solution, which changes the absorption wavelength. This interaction depends on the polarity of the solvent, the refractive index, the coordination power and the chemical structure of the solute. In general, the $\mathrm{Q}$ band wavelength of the phthalocyanine in the solvent shows red-shifting by increasing the refractive index of the solvent. This can best be defined by the Franck-Condon principle. According to this principle, the refraction index and the polarity of the solvent suggest that the species in the solvent can change the absorption wavelength. Thus, it is estimated that the $\mathrm{Q}$ band wavelength in a specific solvent is only related to the refractive index of the solvent, unless the solvent reacts

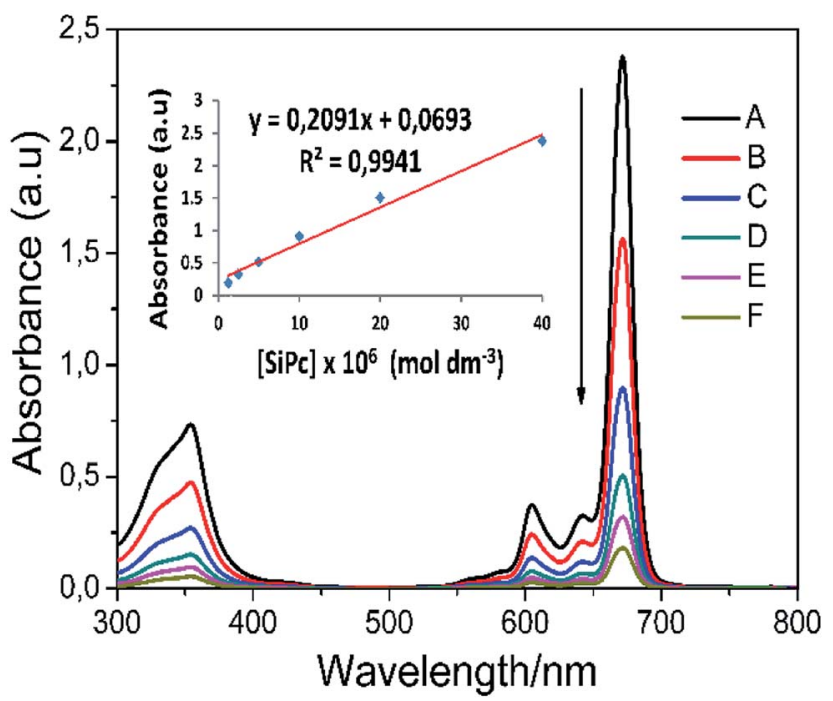

Fig. 4 Electronic absorption spectra of complex 5 in THF at different concentrations: (A) $40 \times 10^{-6}$, (B) $20 \times 10^{-6}$, (C) $10 \times 10^{-6}$, (D) $5 \times$ $10^{-6}$, (E) $2.5 \times 10^{-6}$ (F) $1.25 \times 10^{-6} \mathrm{~mol} \mathrm{dm}^{-3}$. The inset shows the calibration plot for $Q$ band maximum. with the species in the solution or induces any reaction. The electronic absorption spectra of complex $\mathbf{5}$ in different organic solvents (DMSO, DMF, $\mathrm{CH}_{2} \mathrm{CI}_{2}$, and $\mathrm{CHCI}_{3}$ ) and the plot of the $\mathrm{Q}$ band frequency versus the function $\left(n^{2}-1\right) /\left(2 n^{2}+1\right)$, where $n$ is the refractive index of the solvent, ${ }^{36}$ are shown in Fig. 5 . It can be seen that the $\mathrm{Q}$ band frequencies exhibit a linearly dependent on this function which proposes the $\mathrm{Q}$ band wavelength changes directly as the solvation rather than coordination.

3.2.2. Fluorescence studies. First studies to determine a photosensitizer for use in photodynamic therapy are the determination of fluorescence behavior and fluorescent quantum yields. Fluorescence quantum efficiency $\left(\Phi_{\mathrm{F}}\right)$ determines the efficiency of the fluorescence process. In this context, the fluorescence emission, excitation and absorption spectra of novel synthesized zinc(II) phthalocyanine complex (4) and axially disubstituted silicon(rv) phthalocyanine complex (5) examined and these complexes showed similar fluorescence behavior in DMSO (Fig. 6 for complex 4, Fig. 7 for complex 5). The UV-Vis

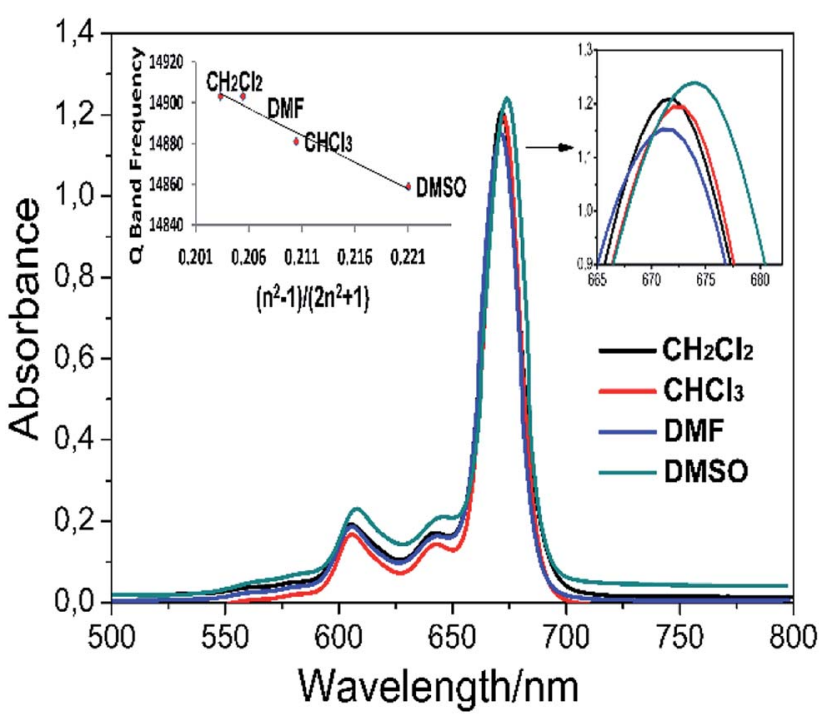

Fig. 5 Absorption spectra of complex 5 in various solvents $(\sim 15 \times$ $10^{-6} \mathrm{~mol} \mathrm{dm}^{-3}$ ). The inset exhibits a plot of the $Q$ band frequency of complex 5 against the function $\left(n^{2}-1\right) /\left(2 n^{2}+1\right)$, where $n$ is the solvents' refractive index. 


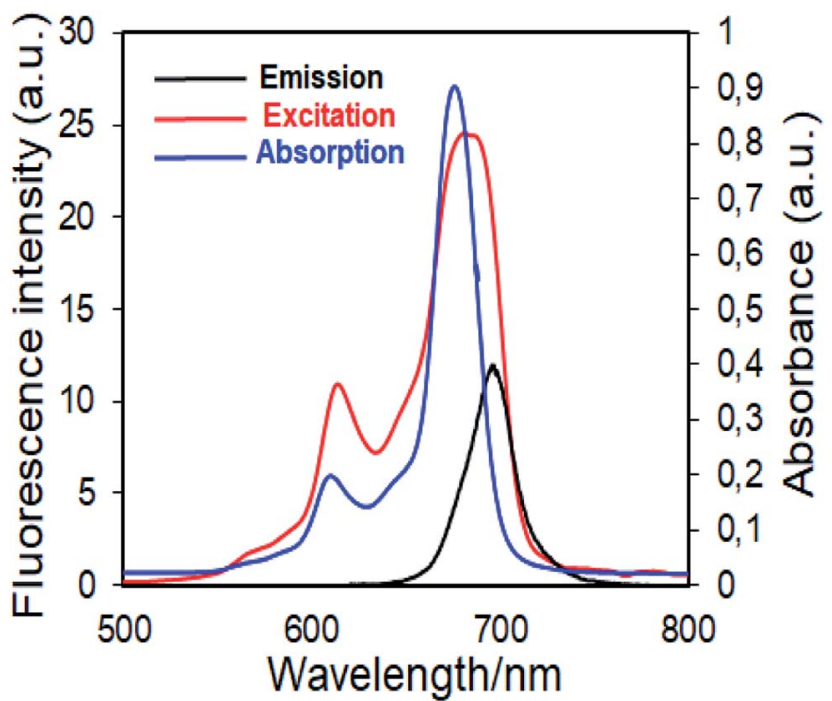

Fig. 6 Electronic absorption, fluorescence emission and excitation spectra of 4 in DMSO. (Excitation wavelength $=697 \mathrm{~nm}$.)

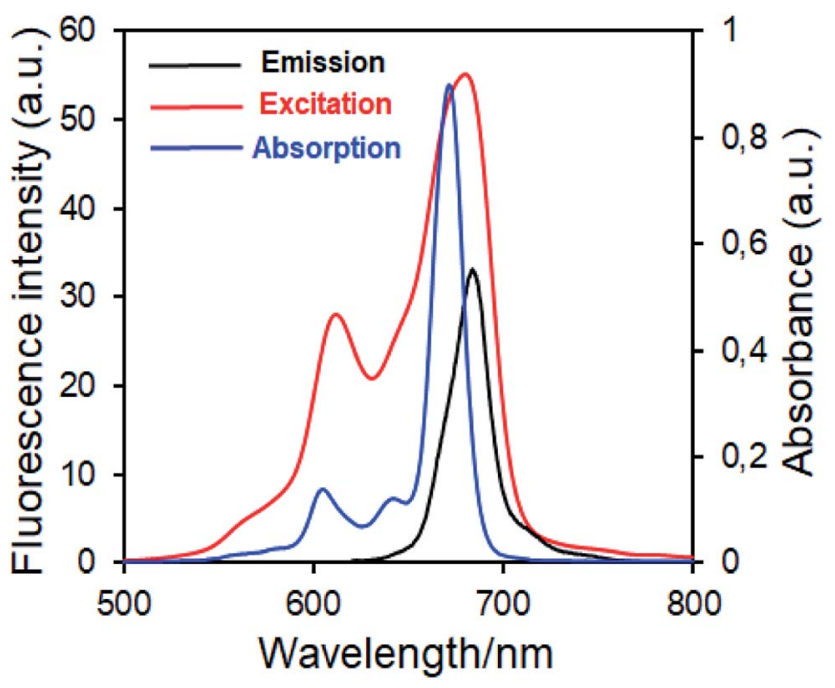

Fig. 7 Electronic absorption, fluorescence emission and excitation spectra of 5 in DMSO. (Excitation wavelength $=686 \mathrm{~nm}$.)

absorption, emission, excitation and fluorescence quantum yield $\left(\Phi_{\mathrm{F}}\right)$ of the complexes $\mathbf{4}$ and $\mathbf{5}$ are given in Table 1.

Fluorescence emission maxima were observed at $691 \mathrm{~nm}$ for complex 4, $679 \mathrm{~nm}$ for compound 5 in DMSO. Stokes shifts from the complexes were detected to be in the same region as the standard phthalocyanines. However, in the case of wavelength results, the excitation spectra of the complexes $\mathbf{4}$ and $\mathbf{5}$ were slightly red-shifted when compared to the absorption spectra, suggesting that the nuclear configurations change the following excitation.

Fluorescence quantum yields of synthesized phthalocyanine complexes were determined using a comparative method. The standards used were $\mathrm{ZnPc}\left(\Phi_{\mathrm{F}}=0.18\right.$ (ref. 37)) for complex 4 in DMSO. The 1,2,3-triazole group containing silicon(Iv) complex (5) showed higher $\Phi_{\mathrm{F}}$ values than zinc(II) complex (4). Although the $\Phi_{\mathrm{F}}$ value of 5 (SiPc) was higher than standard unsubstituted $\mathrm{ZnPc}$ and is lower than unsubstituted $\mathrm{SiPc}(\mathrm{Cl})_{2}$ in DMSO. ${ }^{38}$ Furthermore, the silicon complex (5) shows a higher fluorescence quantum yield than zinc complexes containing 1,2,4-triazole group in the literature, ${ }^{29}$ showing the superiority of the silicon complex over complexes containing similar groups. Fluorescence results revealed that phthalocyanines having the similar substituent; the silicon complex (5) showed a higher fluorescence quantum yield than the zinc complex (4) due to relatively less aggregation in DMSO solution. ${ }^{38}$

3.2.3. Singlet oxygen generation capability studies. It is known that diphenyl isobenzofuran (DPBF) is a single oxygen quencher which causes the formation of endoperoxide species with singlet oxygen in the solution medium and by the chemical addition reaction. The examination of the singlet oxygen capacity of the 1,2,3-triazole group-containing phthalocyanine complexes was carried out in a similar method defined previously in DMSO. ${ }^{13}$

In order to show that the peripherally and axially 1,2,3-triazole group substituted zinc and silicon phthalocyanines are acceptable as useful photosensitizers, the phthalocyanines solution were prepared in a DPBF containing a DMSO solution. Careful control experiments have been carried out to remove other potential sources of media that can effect the absorption decrease. The spectral changes during singlet oxygen determination for complex 4 were given in Fig. 8. No significant change was observed in the absorption spectrum of phthalocyanines when kept in the dark for 21 seconds. (Fig. 8 for zinc complex 4 , Fig. S16† for silicon complex 5.)

Furthermore, the absorption peak belonging to the capture compound DPBF disappeared rapidly within 56 seconds in the irradiation red-light (with $650 \mathrm{~nm}$ cut-on filter) on phthalocyanine solutions. The $\mathrm{Q}$ band intensity of studied zinc and silicon phthalocyanine complexes did not show any changes during the $\Phi_{\Delta}$ determinations, confirming that this complex did not degrade using light irradiation during singlet oxygen studies. The $\Phi_{\Delta}$ values were found 0.76 for zinc complex (4) and for 0.32 silicon complex (5). The $\Phi_{\Delta}$ value of zinc phthalocyanine

Table 1 Optical, photophysical and photochemical properties of the phthalocyanines complexes in DMSO

\begin{tabular}{llllllll}
\hline Dye & $\lambda_{\max }{ }^{a}(\mathrm{~nm})$ & $(\log \varepsilon)$ & $\begin{array}{l}\text { Excitation } \\
\lambda_{\mathrm{Ex}}(\mathrm{nm})\end{array}$ & $\begin{array}{l}\text { Emission } \lambda_{\mathrm{Em}} \\
(\mathrm{nm})\end{array}$ & $\begin{array}{l}\text { Stokes shift } \Delta_{\text {Stokes }} \\
(\mathrm{nm})\end{array}$ & $\begin{array}{l}\text { Fluorescence quantum } \\
\text { yield }\left(\Phi_{\mathrm{F}}\right)\end{array}$ & $\begin{array}{l}\text { Singlet oxygen } \\
\text { quantum yield }\left(\Phi_{\Delta}\right)\end{array}$ \\
\hline $\mathbf{4}$ & 676 & 4.86 & 681 & 691 & 15 & 0.14 & 0.76 \\
5 & 671 & 4.89 & 679 & 679 & 8 & 0.28 & 0.32
\end{tabular}

${ }^{a}$ Absorption maximum wavelength $\left(\lambda_{\max }\right)$ in THF solution. 


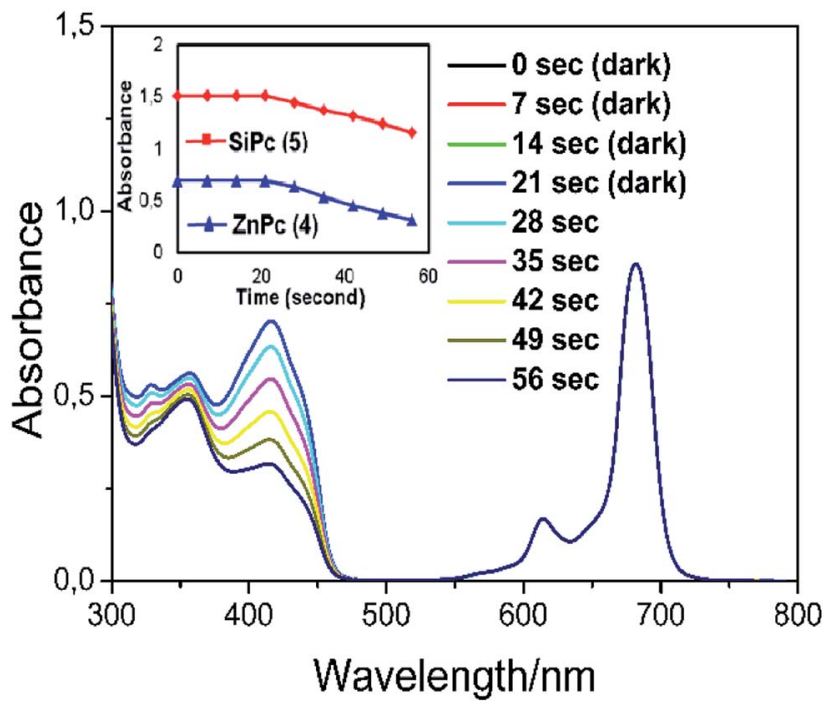

Fig. 8 The reaction of singlet oxygen formed by zinc phthalocyanine complex (4) dissolved in DMSO with 1,3-diphenyl-isobenzofuran (DPBF). For the first $21 \mathrm{~s}$, the solution was kept in the dark; thereafter, it was irradiated with a light source $(650 \mathrm{~nm}$ cut-on filter) for $35 \mathrm{~s}$. The total volume of the solution was set to be $3 \mathrm{~mL}$. The absorption spectra were recorded every 7 seconds. The inset shows plot for DPBF absorbance in phthalocyanine solutions (4 and 5) versus irradiation time (second).

complex is 0.76 and this value is higher than the $\Phi_{\Delta}$ value $\left(\Phi_{\Delta}=\right.$ 0.67 (ref. 39)) of respective unsubstituted $\mathrm{ZnPc}$ reference in DMSO. Similarly, the $\Phi_{\Delta}$ value of silicon phthalocyanine complex is 0.32 and this value is higher than the $\Phi_{\Delta}$ value $\left(\Phi_{\Delta}=\right.$ 0.15 (ref. 38)) of respective unsubstituted $\operatorname{SiPc}(\mathrm{Cl})_{2}$ reference in DMSO. Compared to complexes containing similar triazole substituents in the literature,$^{29,40}$ the zinc complex (4) exhibited a slightly higher singlet oxygen quantum yield value. Consequently, the substitution of the Pc core with 1,2,3-triazole groups increased the generation of singlet oxygen which is very functional for the usability of these Pcs as photosensitizers for PDT applications.

\subsection{Electrochemical studies}

The redox behaviors and energy levels of dyes $\mathbf{4}$ and $\mathbf{5}$ were investigated by using cyclic voltammetry (CV) and square wave voltammetry (SWV) measurements (Fig. 9) and the relevant data are listed in Table 2, along with some optical properties. It can be seen that dyes $\mathbf{4}$ and $\mathbf{5}$ show three and four redox processes, respectively. Compared with dye $\mathbf{4}$, dye $\mathbf{5}$ is not only more hardly oxidized but also more easily reduced owing to the tetra positive nature of silicon..$^{41}$ The redox processes of dye $\mathbf{4}$ are considerably broad, implying that the presence of aggregated species due to the differences in the redox potentials of aggregated and nonaggregated species..$^{42}$ In contrast, the redox processes of dye $\mathbf{5}$ are not broad. This may be due to the absence of aggregated species owing to its nonplanar nature. On the other hand, the oxidation potentials $\left(\mathrm{O}_{1}\right)$ corresponding the HOMO levels of the dyes are more positive than that of the $\mathrm{I}^{-} / \mathrm{I}_{3}{ }^{-}$redox couple $(0.4 \mathrm{~V}$ $v s$. NHE), guaranteeing efficient dye regeneration. ${ }^{43}$ The LUMO value of dye 4 is much more negative than the conduction band (CB) of $\mathrm{TiO}_{2}(-0.5 \mathrm{~V}$ vs. NHE), insuring efficient electron injection from the excited state of the dye to the $\mathrm{TiO}_{2}$ surface. However, the LUMO level of dye $\mathbf{5}$ is slightly more negative than the $\mathrm{CB}$ of $\mathrm{TiO}_{2}$ and electron injection might be less effective. ${ }^{44}$

\subsection{Photovoltaic studies}

Fig. 10 shows the $J-V$ curves and IPCE spectra of the DSSCs based on $\mathbf{4}$ and $\mathbf{5}$ dyes fabricated in the absence and presence of $1 \mathrm{mM}$ CDCA and their photovoltaic parameters are listed in Table 3. All the parameters presented are at optimum conditions. In the absence of CDCA, the short circuit current density $\left.U_{\mathrm{sC}}\right)$ of $3.44 \mathrm{~mA} \mathrm{~cm}^{-2}$ and power conversion efficiency (PCE) of $0.96 \%$ for dye 4 based DSSC are slightly higher than dye $5\left(J_{\mathrm{sC}}=\right.$ $2.41 \mathrm{~mA} \mathrm{~cm} \mathrm{~cm}^{-2}$ and PCE $=0.84 \%$ ). The photovoltaic performance of the former could be attributed to its red-shift absorption and higher dye loading on the $\mathrm{TiO}_{2}$ surface. ${ }^{45}$ This result revealed that the presence of four anchoring groups in the molecular structure of dye 4 results in a more efficient electron injection process into the $\mathrm{TiO}_{2}$ than its counterpart of two
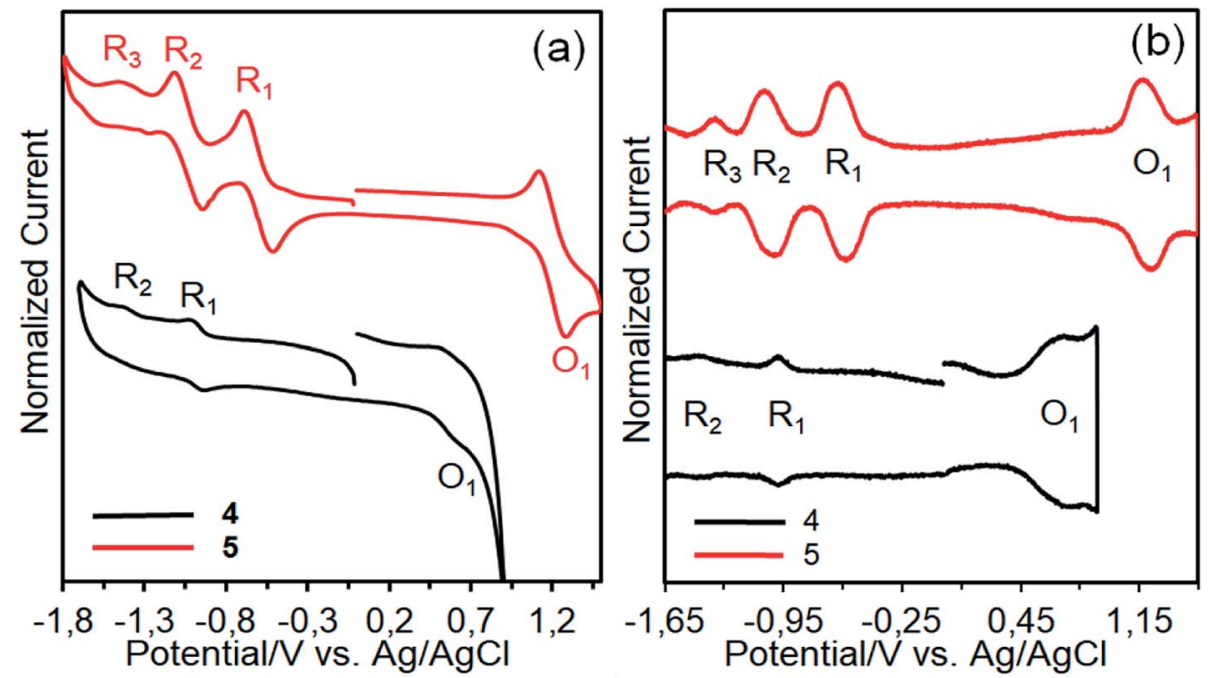

Fig. 9 CVs (a) and SWVs (b) of dyes 4 and 5 on a GCE in $\mathrm{TBABF}_{4} / \mathrm{DMSO}$. 
Table 2 Electro-optical properties of the dyes

\begin{tabular}{lllll}
\hline Dye & $\lambda_{\text {onset }^{a}}(\mathrm{~nm})$ & $E_{0-0}{ }^{b}(\mathrm{eV})$ & $E_{\text {HOMO }}{ }^{c}(\mathrm{~V})$ & $E_{\mathrm{LUMO}}{ }^{d}(\mathrm{~V})$ \\
\hline 4 & 699 & 1.77 & 0.65 & -1.12 \\
5 & 687 & 1.80 & 1.26 & -0.54
\end{tabular}

${ }^{a}$ Absorption onset wavelength ( $\lambda_{\text {onset }}$ ) in THF solution. ${ }^{b}$ The $E_{0-0}$ (band gap) was calculated from the $\lambda_{\text {onset }}$ using $E_{0-0}=1240 / \lambda_{\text {onset }}{ }^{c}$ The $E_{\text {HOMO }}$ was taken from the $E_{1 / 2}$ of the $\mathrm{O}_{1}$ process in Fig. 9. The $E_{1 / 2}$ of $\mathrm{Fc} / \mathrm{Fc}^{+}$was found to be $0.54 \mathrm{~V}, v s$. $\mathrm{Ag} / \mathrm{AgCl}$. By comparing this value with that of $0.63 \mathrm{~V} v s$. NHE, the potentials $v s$. $\mathrm{Ag} / \mathrm{AgCl}$ can be converted to that $v s$. NHE by adding a value of $0.09 \mathrm{~V} .{ }^{d}$ The $E_{\text {LUMo }}$ was estimated with the formula $E_{\mathrm{LUMO}}=E_{\mathrm{HOMO}}-E_{0-0}$.

anchoring groups because the former provides a more effective binding onto the $\mathrm{TiO}_{2}$ surface, which is consistent with the increased dye loading. ${ }^{46}$ On the other hand, the dye 5 molecule can be bonded to the $\mathrm{TiO}_{2}$ surface by only one of the axial anchoring groups. The open-circuit voltage $\left(V_{\mathrm{OC}}\right)$ of the dye $\mathbf{5}$ based device is higher than the dye $\mathbf{4}$ cell, indicating the suppression of charge recombination. Apparently, one of the axial groups, which is unable to bind to the $\mathrm{TiO}_{2}$ surface, favors to the improvement of $V_{\text {OC }}$ because this bulky group can block the $\mathrm{I}_{3}{ }^{-}$ions in the electrolyte from approaching the $\mathrm{TiO}_{2}$ surface, thus reducing the charge recombination rate. ${ }^{47}$ In the presence of CDCA, the cell based on dye 4 showed the highest PCE of $1.30 \%$, which is a $35 \%$ improvement compared with the cell without CDCA. It indicates that this dye forms strong aggregates on the $\mathrm{TiO}_{2}$ surface in the absence of CDCA. In contrast, co-adsorption of dye 5 with CDCA increased the PCE $(0.90 \%)$ of DSSC by around $7 \%$, suggesting that the degree of molecular aggregations was very few. This result demonstrates that the introduction of sterically hindered substituents such as long and flexible axial 1,2,3-triazole units in the dye structures can expeditiously suppress aggregation, owing to disturbance of the $\pi-\pi$ stacking. ${ }^{48}$

The difference in $J_{\mathrm{SC}}$ was further confirmed by IPCE spectra, as a function of the incident light wavelength (Fig. 10b and Table 3). In good agreement with absorption spectra on the $\mathrm{TiO}_{2}$ films, the IPCE spectra for DSSCs based on dye $\mathbf{4}$ are broader than those of dye 5. In the absence of CDCA, the highest IPCE values of DSSCs based on dyes 4 and 5 are 23\% and 19\% at about $690 \mathrm{~nm}$, respectively. However, the highest IPCE values of devices based on dyes $\mathbf{4}$ and $\mathbf{5}$ with the co-adsorbent represent $52 \%$ and $16 \%$ of improvement compared with those of the devices fabricated without the co-adsorbent. This means that the latter is less affected by aggregation issues. Nevertheless, compared with dye $\mathbf{4}$, dye $\mathbf{5}$ is unfavorable for photovoltaic applications due to the axial groups in the molecules significantly reduce the amount of dye loading onto the $\mathrm{TiO}_{2}$ surface, resulting in lowering of the photovoltaic performance. ${ }^{49}$

The $J-V$ curves also display that the $V_{\mathrm{OC}}$ values for DSSCs fabricated with CDCA are slightly improved as compared to those of without CDCA. The improvement of $V_{\mathrm{OC}}$ can be explained by the co-adsorbent occupation of the free $\mathrm{TiO}_{2}$ surface and thereby to suppress the charge recombination. ${ }^{50}$ Electrochemical impedance spectroscopy (EIS) analysis was performed to further verify the $V_{\mathrm{OC}}$ values of the DSSCs in the presence of CDCA (Fig. 11). The Nyquist plots have two semicircles and the right semicircle exhibits the charge recombination resistance between the $\mathrm{TiO}_{2}$ and the electrolyte (Fig. 11a). The radius of the right
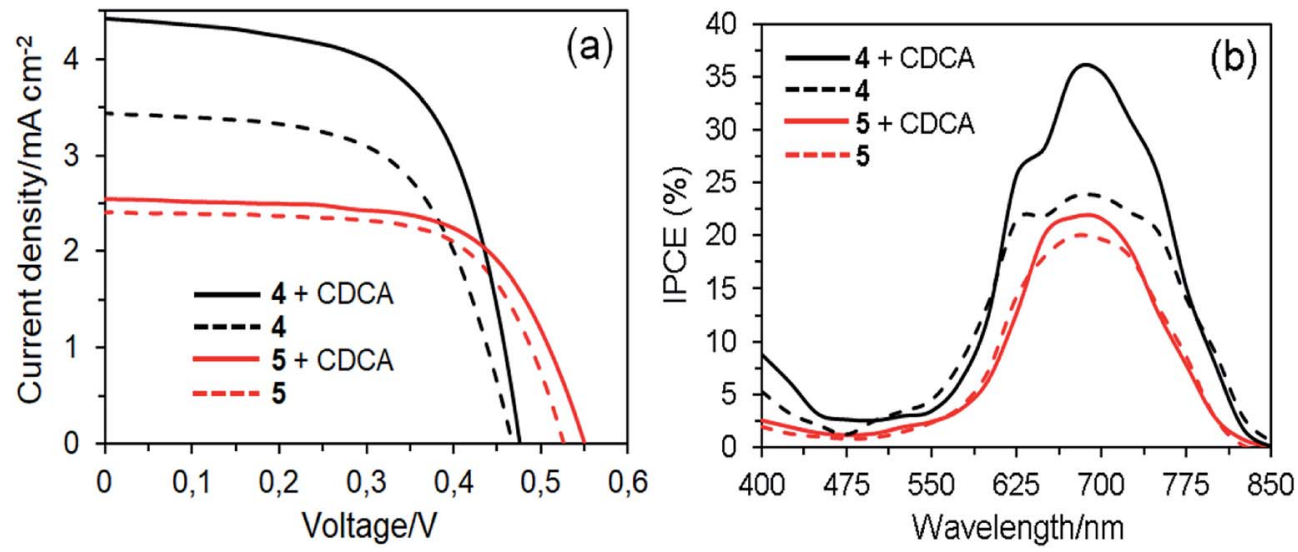

Fig. $10 \mathrm{~J}-V$ curves (a) and IPCE spectra (b) of the DSSCs based on dyes 4 and 5 with and without CDCA.

Table 3 Photovoltaic parameters of the DSSCs using ethanol/THF (1/1) as a dye-loading solvent mixture

\begin{tabular}{|c|c|c|c|c|c|c|c|}
\hline Dye & CDCA $(\mathrm{mM})$ & $\begin{array}{l}\text { IPCE integrated current } \\
\text { density }\left(\mathrm{mA} \mathrm{cm} \mathrm{cm}^{-2}\right)\end{array}$ & $J_{\mathrm{SC}}\left(\mathrm{mA} \mathrm{cm}^{-2}\right)$ & $V_{\mathrm{OC}}(\mathrm{V})$ & $\mathrm{FF}$ & PCE (\%) & $\begin{array}{l}\text { Dye-loaded } \\
\text { amount }\left(\mathrm{mol} \mathrm{cm}^{-2}\right)\end{array}$ \\
\hline 4 & 0.00 & 3.48 & 3.44 & 0.467 & 0.60 & 0.96 & $3.69 \times 10^{-8}$ \\
\hline 5 & 0.00 & 2.40 & 2.41 & 0.526 & 0.66 & 0.84 & $2.86 \times 10^{-8}$ \\
\hline 5 & 1.00 & 2.48 & 2.53 & 0.550 & 0.65 & 0.90 & $2.68 \times 10^{-8}$ \\
\hline
\end{tabular}



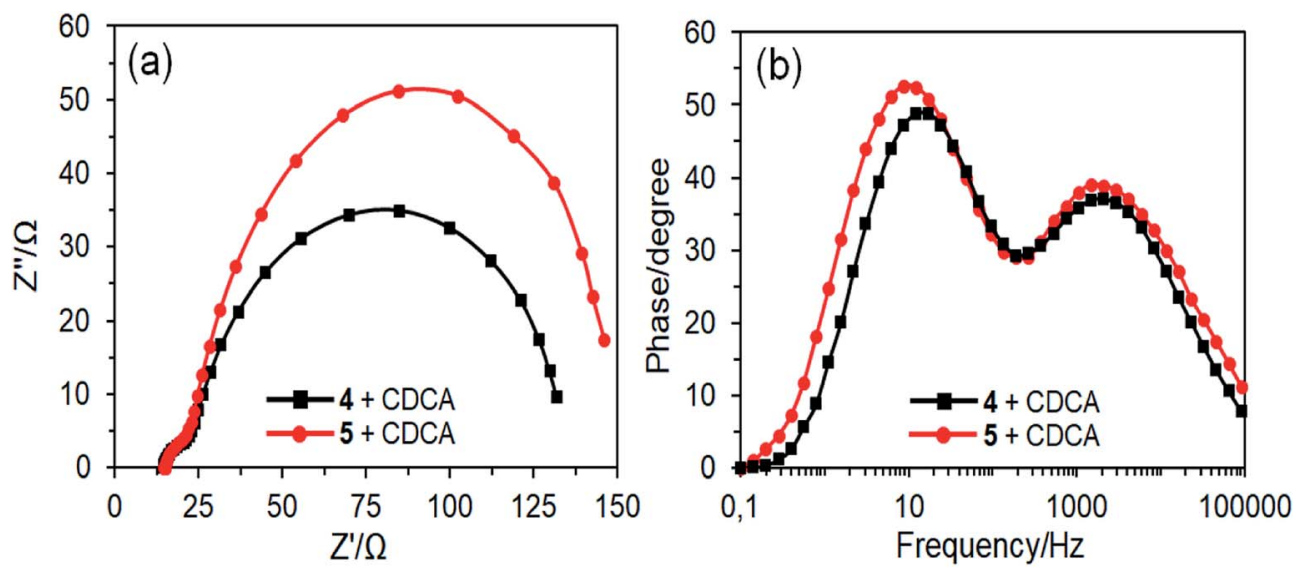

Fig. 11 Nyquist (a) and Bode (b) plots of DSSCs based on dyes 4 and 5 with CDCA in the dark.

semicircle of DSSC based on dye $\mathbf{5}$ is higher than that of dye $\mathbf{4}$, which is agreement with their $V_{\mathrm{OC}}$ values. The frequency maxima $(f)$ of the left peaks in the Bode plots for DSSCs based on dyes 4 and 5 are 12.19 and $8.65 \mathrm{~Hz}$, respectively (Fig. 11b). The corresponding electron lifetimes $\left(\tau_{\mathrm{e}}\right)$, which can be estimated using equation $\tau_{\mathrm{e}}=1 / 2 \pi f,{ }^{51}$ are 13.06 and $18.4 \mathrm{~ms}$, respectively, which is consistent with the $V_{\mathrm{OC}}$ values.

\section{Conclusion}

As a consequence, in this work, the preparation, spectral characterization, aggregation, photophysical, singlet oxygen capability, electrochemical and photovoltaic properties of novel peripherally substituted zinc and axially disubstituted silicon phthalocyanine complexes are presented for the first time. The photophysical and singlet oxygen generation properties of axially substituted silicon and peripherally substituted zinc phthalocyanine complexes were investigated in DMSO. The 1,2,3-triazole group containing silico$\mathrm{n}$ (Iv) complex (5) showed higher $\Phi_{\mathrm{F}}$ values than zinc(II) complex (4) and standard unsubstituted ZnPc. Also, the studied zinc complex (4) is produced efficiently singlet oxygen $\left(\Phi_{\Delta}=0.76\right)$ in DMSO. These photophysical and photochemical results indicate that the synthesized phthalocyanine complexes (especially zinc complex) may be alternative to clinically approved photosensitizers with good solubility, red-shifts in the absorption spectrum, nonaggregating behaviors, and acceptable singlet oxygen quantum yields. Compared to complex 5, complex $\mathbf{4}$ exhibited red-shifted absorption and higher dye loading, which is beneficial for absorbing more photons and thus generating high photocurrent. On the other hand, the power conversion efficiencies of solar cells based on complexes $\mathbf{4}$ and $\mathbf{5}$ with the co-adsorbent improved by $35 \%$ and $7 \%$, respectively, indicating that the introduction of axial 1,2,3-triazole groups may be able to play an anti-aggregation effect. This study has shown that these zinc and silicon phthalocyanines are promising photosensitizers for both photodynamic cancer therapy and dye-sensitized solar cell applications.

\section{Conflicts of interest}

There are no conflicts to declare.

\section{Acknowledgements}

The author wishes to thank Assoc. Prof. Dr İ. Şişman for his excellent technical support in electrochemical and photovoltaic measurements and helpful discussion.

\section{References}

1 C.-X. Tan, Y.-X. Shi, J.-Q. Weng, X.-H. Liu, B.-J. Li and W.-G. Zhao, Lett. Drug Des. Discovery, 2012, 9, 431-435.

2 D. K. Dalvie, A. S. Kalgutkar, S. C. Khojasteh-Bakht, R. S. Obach and J. P. O'Donnell, Chem. Res. Toxicol., 2002, 15, 269-293.

3 W. Seth Horne, M. K. Yadav, A. C. David Stout and M. R. Ghadiri, J. Am. Chem. Soc., 2004, 126, 15366-15367.

4 S. Zhang, Z. Xu, C. Gao, Q.-C. Ren, L. Chang, Z.-S. Lv and L.-S. Feng, Eur. J. Med. Chem., 2017, 138, 501-513.

5 S. G. Agalave, S. R. Maujan and V. S. Pore, Chem.-Asian J., 2011, 6, 2696-2718.

6 Y. Ooyama, S. Inoue, T. Nagano, K. Kushimoto, J. Ohshita, I. Imae, K. Komaguchi and Y. Harima, Angew. Chem., Int. Ed., 2011, 50, 7429-7433.

7 L. Sobotta, S. Lijewski, J. Dlugaszewska, J. Nowicka, J. Mielcarek and T. Goslinski, Inorg. Chim. Acta, 2019, 489, 180-190.

8 N. Yesilgul, T. B. Uyar, O. Seven and E. U. Akkaya, ACS Omega, 2017, 2, 1367-1371.

9 E. Güzel, A. Atsay, S. Nalbantoglu, N. Şaki, A. L. Dogan, A. Gül and M. B. Koçak, Dyes Pigm., 2013, 97, 238-243.

10 E. Güzel, İ. Şişman, A. Gül and M. B. Koçak, J. Porphyrins Phthalocyanines, 2019, 23, 279-286.

11 M. Urbani, M.-E. Ragoussi, M. K. Nazeeruddin and T. Torres, Coord. Chem. Rev., 2019, 381, 1-64.

12 B. Yıldız, E. Güzel, N. Menges, İ. Şişman and M. Kasım Şener, Sol. Energy, 2018, 174, 527-536.

13 E. Güzel, N. Şaki, M. Akın, M. Nebioğlu, İ. Şişman, A. Erdoğmuş and M. B. Koçak, Synth. Met., 2018, 245, 127134.

14 E. Güzel, G. Yaşa Atmaca, A. Erdoğmuş and M. B. Koçak, J. Coord. Chem., 2017, 70, 2659-2670. 
15 F. Dumoulin, M. Durmuş, V. Ahsen and T. Nyokong, Coord. Chem. Rev., 2010, 254, 2792-2847.

16 M. Göksel, M. Durmuș and D. Atilla, Photochem. Photobiol. Sci., 2016, 15, 1318-1329.

17 M. V. Martínez-Díaz, G. de la Torre and T. Torres, Chem. Commun., 2010, 46, 7090.

18 E. Güzel, Ş. Çetin, A. Günsel, A. T. Bilgiçli, İ. Şişman and M. N. Yarasir, Res. Chem. Intermed., 2018, 44, 971-989.

19 M. K. Şener, A. Gül and M. B. Koçak, J. Porphyrins Phthalocyanines, 2003, 7, 617-622.

20 B. Akkurt and E. Hamuryudan, Dyes Pigm., 2008, 79, 153158.

21 C. Kantar, N. Akdemir, E. Ağar, N. Ocak and S. Şaşmaz, Dyes Pigm., 2008, 76, 7-12.

22 N. Kabay and Y. Gök, Tetrahedron Lett., 2013, 54, 4086-4090.

23 S. Z. Yildiz, M. Küçükislamoǧlu and M. Tuna, J. Organomet. Chem., 2009, 694, 4152-4161.

24 M. Ozer, F. Yilmaz, H. Erer, I. Kani and O. Bekaroglu, Appl. Organomet. Chem., 2009, 23, 55-61.

25 E. Güzel, A. Koca and M. B. Koçak, Supramol. Chem., 2017, 29, 536-546.

26 R. Z. Uslu Kobak, E. S. Öztürk, A. Koca and A. Gül, Dyes Pigm., 2010, 86, 115-122.

27 H. Karaca, S. Sezer, Ş. Özalp-Yaman and C. Tanyeli, Polyhedron, 2014, 72, 147-156.

28 Ü. Demirbaş, D. Akyüz, A. Mermer, H. T. Akçay, N. Demirbaș, A. Koca and H. Kantekin, Spectrochim. Acta, Part A, 2016, 153, 478-487.

29 H. T. Akçay, M. Pişkin, Ü. Demirbaş, R. Bayrak, M. Durmuş, E. Menteşe and H. Kantekin, J. Organomet. Chem., 2013, 745746, 379-386.

30 R. Bayrak, O. Bekircan, M. Durmuş and I. Deǧirmencioğlu, J. Organomet. Chem., 2014, 767, 101-107.

31 A. Aktaş, D. Ünlüer, R. Z. U. Kobak, İ. Acar, E. Düğdü, A. Koca and H. Kantekin, Inorg. Nano-Met. Chem., 2017, 47, 830-840.

32 J. T. Simmons, J. R. Allen, D. R. Morris, R. J. Clark, C. W. Levenson, M. W. Davidson and L. Zhu, Inorg. Chem., 2013, 52, 5838-5850.
33 H. Baş and Z. Biyiklioglu, J. Organomet. Chem., 2015, 791, 238-243.

34 Z. Chen, Y. Wu and X. Zuo, Dyes Pigm., 2007, 73, 245-250.

35 H. Matsuzaki, T. N. Murakami, N. Masaki, A. Furube, M. Kimura and S. Mori, J. Phys. Chem. C, 2014, 118, 1720517212.

36 N. S. Bayliss, J. Chem. Phys., 1950, 18, 292.

37 A. Ogunsipe, J. Chen and T. Nyokong, New J. Chem., 2004, 28, 822-827.

38 G. Y. Atmaca, C. Dizman, T. Eren and A. Erdoğmuş, Spectrochim. Acta, Part A, 2015, 137, 244-249.

39 I. Gürol, M. Durmuş, V. Ahsen and T. Nyokong, Dalton Trans., 2007, 3782.

40 A. Nas, S. Fandakl, H. Kantekin, A. Demirbaș and M. Durmuş, Dyes Pigm., 2012, 95, 8-17.

41 N. Masilela, M. Idowu and T. Nyokong, J. Photochem. Photobiol., A, 2009, 201, 91-97.

42 M. Çamur, M. Durmuş, A. Riza Özkaya and M. Bulut, Inorg. Chim. Acta, 2012, 383, 287-299.

43 W. Ying, J. Yang, M. Wielopolski, T. Moehl, J.-E. Moser, P. Comte, J. Hua, S. M. Zakeeruddin, H. Tian and M. Grätzel, Chem. Sci., 2014, 5, 206-214.

44 K. D. Seo, I. T. Choi and H. K. Kim, Chem.-Eur. J., 2015, 21, 14804-14811.

45 R. Misra, R. Maragani, K. R. Patel and G. D. Sharma, RSC Adv., 2014, 4, 34904-34911.

46 K. Ladomenou, V. Nikolaou, G. Charalambidis and A. G. Coutsolelos, Dalton Trans., 2016, 45, 1111-1126.

47 T. Ikeuchi, H. Nomoto, N. Masaki, M. J. Griffith, S. Mori and M. Kimura, Chem. Commun., 2014, 50, 1941-1943.

48 Y. Ooyama and Y. Harima, Eur. J. Org. Chem., 2009, 29032934.

49 S.-G. Chen, H.-L. Jia, X.-H. Ju and H.-G. Zheng, Dyes Pigm., 2017, 146, 127-135.

50 X. Kang, J. Zhang, A. J. Rojas, D. O'Neil, P. Szymanski, S. R. Marder and M. A. El-Sayed, J. Mater. Chem. A, 2014, 2, 11229-11234.

51 Y. Wang, C. Yang, J. Chen, H. Qi, J. Hua, Y. Liu, E. Baranoff, H. Tan, J. Fan and W. Zhu, Dyes Pigm., 2016, 127, 204-212. 